\title{
Effect of Atrazine on Growth, Photosynthesis, and Between-Strain Variability in Scenedesmus subspicatus (Chlorophyceae)
}

\author{
R. Behra, G. P. Genoni, A. L. Joseph \\ Swiss Federal Institute for Environmental Science and Technology (EAWAG), CH-8600 Duebendorf, Switzerland
}

Received: 2 February 1998/Accepted: 26 January 1999

\begin{abstract}
The magnitude of between-strain differences in the sensitivity of algal species to toxicants is not well known. Yet, informations obtained with a single strain are used for ecotoxicological assessment and for interspecific comparisons. Using 12 strains, we determined whether intraspecific variability occurs in the green alga Scenedesmus subspicatus. We examined growth, photosynthetic activity, and short-term sensitivity thereof to the herbicide atrazine $\left(500 \mu \mathrm{g} \cdot \mathrm{L}^{-1}\right)$ as well as how these responses are affected by chronic exposure to low atrazine concentrations $\left(0,1,5\right.$, and $\left.20 \mu \mathrm{g} \cdot \mathrm{L}^{-1}\right)$. Independent of chronic exposure to atrazine, the strains differed in growth rate and photosynthesis rate. Yet the short-term sensitivity to atrazine was affected by the chronic treatments. All but one strain became more tolerant, their short-term sensitivity being inversely related to the applied atrazine concentration and dependent on the duration of exposure. Differences in response to increments in atrazine concentration resulted in differences in rank order of sensitivity of strains. Moreover, between-strain variability was markedly higher in the atrazine treatments than in the controls. These results can be explained by the significant role of genotype versus environment interactions in determining intraspecific differences in adaptive physiological responses of $S$. subspicatus to chronic exposure to atrazine.
\end{abstract}

The prediction of the effects of chemicals on phytoplankton relies mainly on relatively simple ecotoxicological tests with a small number of algal species. Tests on single strains are often used to measure the sensitivity of a species and to derive water quality standards aimed at protecting the natural populations of (at least) that species.

Yet, genetic diversity in important ecological traits has been shown to occur in natural populations of phytoplankton species (as reviewed in Wood and Leatham 1992). In fact, betweenstrain and interclonal variability has been detected for most of the physiological and biochemical characters that have been investigated. Because sensitivity to pollutants is influenced by the molecular make-up of the target cells, some degree of intraspecific variability may be expected to occur in the

Correspondence to: R. Behra tolerance to toxicants. Indeed, differences in sensitivity to toxicants were found in some species between strains differing in geographic origin (Menzel et al. 1970; Fisher et al. 1973; Murphy and Belastock 1980). Broad intraspecific differences in tolerance to various metals were found between various pristine sites and between pristine and polluted sites (Foster 1982). This points to the role of the exposure history of individuals as another factor in causing intraspecific differences in tolerance to pollutants.

Thus, between-strain differences in the response to exposure to chemicals can be partitioned into genetic variability $(\mathrm{g})$, environmental variability (e), and the interaction of these two $(\mathrm{g} \times \mathrm{e})$ (Hoffmann and Parsons 1991). The genetic component shows in the different response of two or more strains in one environment and the environmental component in the different response of one strain to different environments. The $\mathrm{g} \times \mathrm{e}$ interaction shows in the differential effect of an increasing exposure concentrations on different strains. Moreover, some strains may be better adapted to the conditions prevailing before exposure, whereas other strains may, through the acquisition of tolerance, fare better under the new conditions. Therefore, the ranking of sensitivity among strains will not necessarily be the same before and after exposure.

Few studies have examined the variability in sensitivity to toxicants among strains, clones, or individuals of aquatic species and the effect of exposure history on sensitivity changes (Baird et al. 1991; Münziger and Monicelli 1991; Soares et al. 1992; Forbes et al. 1995). Even less is known on intraspecific sensitivity differences in algae (Foster 1982; Hersh and Crumpton 1989), though such knowledge bears on the relevance of ecotoxicological testing on single strains as representative of a species. Taking this variability into account may contribute to a more realistic prediction of safe concentrations for natural populations than using data on single strains (Forbes and Forbes 1994).

The purpose of this study was to examine whether intraspecific variability occurs among 12 strains of the green alga Scenedesmus subspicatus. The traits that we examined were growth, photosynthetic activity, and short-term tolerance to an inhibitor of photosynthesis, the herbicide atrazine. Moreover, we investigated whether growth and photosynthetic responses are affected differently by a chronic exposure to a low atrazine level. Differences between strains were analyzed in terms of the sources of variability, that is, $\mathrm{g}, \mathrm{e}$, and $\mathrm{g} \times \mathrm{e}$. 


\section{Materials and Methods}

\section{Strains and Culture Conditions}

We used 12 clones of $S$. subspicatus Chod. 1926 (Chlorophyceae) that differed in their geographic origin (Table 1) and morphology. The strains were kindly supplied by E. Hegewald and U. G. Schlösser (culture collections of Jülich and Göttingen, Germany). They were held separately as axenic batch cultures in a medium at $\mathrm{pH}$ 7.2, containing $75 \mathrm{mg} \cdot \mathrm{L}^{-1} \mathrm{MgSO}_{4} \cdot 7 \mathrm{H}_{2} \mathrm{O}, 500 \mathrm{mg} \cdot \mathrm{L}^{-1} \mathrm{NaNO}_{3}, 330 \mathrm{mg} \cdot \mathrm{L}^{-1}$ $\mathrm{NH}_{4} \mathrm{NO}_{3}, 39.6 \mathrm{mg} \cdot \mathrm{L}^{-1} \mathrm{~K}_{2} \mathrm{HPO}_{4}, 35 \mathrm{mg} \cdot \mathrm{L}^{-1} \mathrm{CaCl}_{2} \cdot 2 \mathrm{H}_{2} \mathrm{O}, 43.6$ $\mathrm{mg} \cdot \mathrm{L}^{-1} \mathrm{Na}_{2} \mathrm{CO}_{3}, 6 \mathrm{mg} \cdot \mathrm{L}^{-1}$ citric acid, $2.9 \mathrm{mg} \cdot \mathrm{L}^{-1} \mathrm{H}_{3} \mathrm{BO}_{3}, 1.81$ $\mathrm{mg} \cdot \mathrm{L}^{-1} \mathrm{MnCl}_{2}, 0.11 \mathrm{mg} \cdot \mathrm{L}^{-1} \mathrm{ZnCl}_{2}, 0.08 \mathrm{mg} \cdot \mathrm{L}^{-1} \mathrm{CuSO}_{4} \cdot 4 \mathrm{H}_{2} \mathrm{O}$, $0.018 \mathrm{mg} \cdot \mathrm{L}^{-1}\left(\mathrm{NH}_{4}\right)_{6} \mathrm{Mo}_{7} \mathrm{O}_{24} \cdot 4 \mathrm{H}_{2} \mathrm{O}, 2.5 \mathrm{mg} \cdot \mathrm{L}^{-1} \mathrm{FeCl}_{3} \cdot 6 \mathrm{H}_{2} \mathrm{O}, 1$ $\mathrm{mg} \cdot \mathrm{L}^{-1} \mathrm{Na}_{2} \mathrm{EDTA} \cdot 2 \mathrm{H}_{2} \mathrm{O}$. The clonal cultures were maintained at $21^{\circ} \mathrm{C}$ under a continuous illumination of $30 \mu \mathrm{E} \cdot \mathrm{m}^{-2} \cdot \mathrm{s}^{-1}$ provided by cool-white fluorescent lamps. The strains were acclimated to these culture conditions, as described by Brand and Guillard (1981). We sequentially established new batch cultures by transferring an inoculum from an early exponentially growing batch culture before the culture populations depleted the nutrients in the medium. Acclimation was considered to be complete when the exponential growth rate of successive cultures were the same. For the experiments described hereafter, an aliquot $(0.05-1 \mathrm{ml})$ from each acclimated test culture in early exponential growth phase was added to $80 \mathrm{ml}$ of medium in a 200-ml Erlenmeyer flask to yield an initial cell density of $10^{5}$ cells $\cdot \mathrm{ml}^{-1}$.

\section{Experimental Procedures}

Twelve strains were cultured for 60 days and examined for their growth rates, photosynthetic activity, and short-term sensitivity thereof to an exposure of $30 \mathrm{~min}$ to $500 \mu \mathrm{g} \cdot \mathrm{L}^{-1}$ atrazine (6-chloro-N-ethyl- $\mathrm{N}-(1$ mehylethyl)-1,3,5-triazine-2,4-diamine). To investigate the effect of chronic exposure to atrazine, each strain also was cultured in medium with $5 \mu \mathrm{g} \cdot \mathrm{L}^{-1}$ atrazine for the same time period. Additionally, five strains $\left(1,2,5,6\right.$, and 12) were exposed to $1 \mu \mathrm{g} \cdot \mathrm{L}^{-1}$ and $20 \mu \mathrm{g} \cdot \mathrm{L}^{-1}$ atrazine.

Population growth was measured daily as the temporal change in optical density (OD) at $680 \mathrm{~nm}$ (Uvikon 930, Kontron Instruments). The linear function of $\mathrm{OD}_{680}$ versus cell density was derived initially by direct microscope counts of algal cells at $100 \times$ magnification in a Neubauer cell. To minimize self-shading, which was noticeable at $\mathrm{OD}_{680}>0.6$, samples were diluted when exceeding that value. Growth rates during the exponential growth phase were calculated by linear regression of $\ln \left(\mathrm{OD}_{680}\right)$ against time (Stein 1973).

Photosynthetic activity was expressed as the net oxygen evolution. To measure oxygen evolution and its short-term sensitivity to atrazine, aliquots of the algal culture were washed three times with culture medium and then resuspended in medium to obtain a cell density with an $\mathrm{OD}_{680}$ between 0.15 and 0.40 . The algae were incubated for $20 \mathrm{~min}$ in the dark in the absence or presence of $500 \mu \mathrm{g} \cdot \mathrm{L}^{-1}$ of atrazine (see below). Preliminary experiments showed that at this atrazine concentration an incubation in the dark of about $10 \mathrm{~min}$ was sufficient to induce maximal inhibition of oxygen evolution. After that time, $2 \mathrm{ml}$ of the algal suspension were placed in a glass incubation chamber equipped with a Clark oxygen electrode and a magnetic stirrer (Rank Brothers, Cambridge, UK; Delieu and Walker 1972). The temperature was maintained at $21^{\circ} \mathrm{C}$. To measure the rate of oxygen consumption by respiration, the algae were kept in the dark for another $10 \mathrm{~min}$. Then, the algae were provided with an illumination of $120 \mu \mathrm{E} \cdot \mathrm{m}^{-2} \cdot \mathrm{s}^{-1}$ from a 35-W halogen lamp, and net oxygen evolution was recorded during $10 \mathrm{~min}$. Rates of oxygen consumption or evolution were calculated from the linear part of the curves. For comparisons between strains, the net oxygen evolution was related to the $\mathrm{OD}_{680}$ of the algal suspensions
Table 1. Designation and geographic origin of the strains of Scenedesmus subspicatus examined

\begin{tabular}{|c|c|}
\hline Strain & Origin \\
\hline 1 Hegewald 1971-67 & Hungary \\
\hline 2 Hegewald 1973-374 & Peru \\
\hline 3 Hegewald $1975-272$ & Germany \\
\hline 4 Hegewald $1980-24$ & Germany \\
\hline 5 Hegewald 1981-23 & Indonesia \\
\hline 6 Hegewald $1981-42$ & Singapore \\
\hline 7 Hegewald $1988-30$ & New Zealand \\
\hline 8 Hegewald 1988-54 & New Zealand \\
\hline 9 Payer $1971-124$ & Thailand \\
\hline 10 Bai $1971-41$ & Hungary \\
\hline 11 Felföldy 5640 & Hungary \\
\hline 12 SAG 86.81 & Germany \\
\hline
\end{tabular}

and expressed as $\mu \mathrm{M} \mathrm{O}_{2} \cdot \min ^{-1} \cdot \mathrm{OD}^{-1}$. The inhibition of oxygen evolution by atrazine was calculated by dividing the rates before addition of atrazine by the corresponding rates after addition, and expressed as the percent difference between the control and the treated sample. The variability between measurements required that each measurement be done twice, as indicated by a one-tailed $t$ test on untreated samples (Gad and Weil 1989).

Technical grade atrazine (purity $>99 \%$ ) was obtained from Riedel-de Haen. Aqueous solutions were used. Atrazine concentrations were determined by HPLC chromatography with a Vidac C18 column $(25 \mathrm{~cm} \times 4.6 \mathrm{~mm})$ and methanol as a solvent. Samples were prepared for analysis as described by Davoli et al. (1987). The atrazine was detected spectrophotometrically at $221 \mathrm{~nm}$. In that way we determined the atrazine concentration of the stock solution $\left(28.9 \mathrm{mg} \cdot \mathrm{L}^{-1}\right)$ and in the chronically exposed cultures of strain 6 after 38 days of culturing. At that time the effective concentrations in cultures exposed to nominal concentrations 1,5 , and $20 \mu \mathrm{g} \cdot \mathrm{L}^{-1}$ were $0.80,3.42$, and 14.14 $\mu \mathrm{g} \cdot \mathrm{L}^{-1}$, respectively.

\section{Data Analysis}

Data analyses were done with Excel (Microsoft Corp.), StatView (Feldman et al. 1987), and SAS (SAS Institute, Cary, NC). The sources of variability between strains in their physiological traits and in their response to atrazine were tested as follows. A multivariate ANOVA was performed on oxygen evolution and short-term sensitivity to atrazine with a test of the effects of strain (i.e., "genotype"), of atrazine concentration in the chronic exposure (i.e., "environment"), and of the interaction (i.e., "genotype $\times$ environment"). The assumption of normality was tested by two-tailed tests on skewness and kurtosis; the assumption of homogeneity of variances was tested by F tests (Sokal and Rohlf 1981). Log-transformed data met those assumptions, except for comparisons of growth rates between strains. The latter comparisons were made on untransformed data by the nonparametric KruskalWallis one-way analysis of variance, with a test of the effect of chronic exposure concentration and of strain.

\section{Results}

Variability in Growth Rate, Photosynthetic Activity, and Short-Term Response to Atrazine

The 12 strains differed in their growth, as indicated by the time needed for the control cultures to reach the stationary growth 
phase: Strains 3, 4, and 5 did so by day 25 ; strain 7 by day 30 ; and strains $8,9,12$, and 13 by day 60 ; whereas strains $1,2,6$, and 10 were still in exponential growth at day 60 (not shown). The highest and lowest growth rates differed by a factor of $\sim 13$, with values ranging from 0.028 to $0.360 \mathrm{OD} \cdot \mathrm{day}^{-1}$. However, except for strains $3(\mu=0.36)$ and $4(\mu=0.136)$, growth rates were similar (Table 2). Attempts to relate differences in growth rates to the morphological characteristics of the strains were negative.

The 12 strains also differed in their photosynthetic activity, which varied from 2.32 to $12.76 \mu \mathrm{M} \mathrm{O}_{2} \cdot \mathrm{min}^{-1} \cdot \mathrm{OD}^{-1}$ during early exponential growth (Table 3 ). The photosynthetic activity of each strain, as shown for five strains in Figure 1, changed during growth, with maximal activities generally found during the early exponential phase, followed by a decline during the transition to the stationary phase. This was due only in part to a higher respiration which, depending on the strain, contributed $1.0-33.3 \%$ during early exponential growth and 3.5-34.2\% later in growth to the observed decrease in net photosynthesis (not shown). Rather, it was mainly due to a decrease in the gross photosynthesis of each strain.

Finally, the 12 strains also differed in the short-term response of photosynthetic activity to $500 \mu \mathrm{g} \cdot \mathrm{L}^{-1}$ atrazine. Inhibition ranged from $36.4 \%$ to $105.6 \%$ during early exponential growth (Table 3). For most strains, sensitivity to atrazine declined during growth, as shown for five strains in Figure 2, and was not correlated to the growth rate or the photosynthetic activity of each strain.

\section{Effect of Chronic Exposure to Atrazine on Growth Rate, Photosynthetic Activity, and Short-Term Response to Atrazine}

Exposure of strains to 1,5 , or $20 \mu \mathrm{g} \cdot \mathrm{L}^{-1}$ atrazine did not significantly affect growth rate (Table 2). Yet, as measured for strain 6 , the effective atrazine concentrations were still high at day $38\left(0.80,3.42\right.$, and $14.14 \mu \mathrm{g} \cdot \mathrm{L}^{-1}$, respectively $)$. A test for the effect of chronic exposure concentration indicated that the inhibition observed in the atrazine treatments was similar and not different from the control $(\mathrm{H}=1.08, \mathrm{p}>0.78, \mathrm{df}=3$, $\mathrm{n}=34)$. Rather, strain was a significant cause for the differences in growth rates $(\mathrm{H}=30.3, \mathrm{p}<0.005, \mathrm{df}=11, \mathrm{n}=34)$.

Exposure of strains to 1,5 , or $20 \mu \mathrm{g} \cdot \mathrm{L}^{-1}$ atrazine did not significantly affect photosynthetic activity (Table 3, Figure 1). As for the control cultures, oxygen evolution of the strains decreased with time in culture in all treatments (Figure 1). The strains exposed only to $5 \mu \mathrm{g} \cdot \mathrm{L}^{-1}$ atrazine behaved in a similar manner (not shown). Analysis of the photosynthetic data obtained with the control and with the treated cultures indicates that differences in oxygen evolution depend on the strains, but not on the exposure to atrazine (Table 4).

In contrast to the photosynthetic rate, the short-term sensitivity of the photosynthetic activity to $500 \mu \mathrm{g} \cdot \mathrm{L}^{-1}$ atrazine was affected by the chronic exposure to atrazine (Table 3, Figure 2). Generally, during the first days of exposure, sensitivity increased relative to the controls. Within 15 to 20 days, however, the tolerance (except for strain 12) increased at a rate proportional to the exposure concentration. Analysis of the data confirmed that the sensitivity of oxygen evolution to short-term atrazine exposure depends on the atrazine concentration in the
Table 2. Growth rates of various strains of Scenedesmus subspicatus treated with $0,1,5$, and $20 \mu \mathrm{g} \cdot \mathrm{L}^{-1}$ atrazine

\begin{tabular}{cllll}
\hline \multirow{5}{*}{ Strain } & \multicolumn{4}{l}{ Growth rate $\left(\mathrm{OD} \cdot \mathrm{day}^{-1}\right)$} \\
\cline { 2 - 5 } & $0\left(\mu \mathrm{g} \cdot \mathrm{L}^{-1}\right)$ & $1\left(\mu \mathrm{g} \cdot \mathrm{L}^{-1}\right)$ & $5\left(\mu \mathrm{g} \cdot \mathrm{L}^{-1}\right)$ & $20\left(\mu \mathrm{g} \cdot \mathrm{L}^{-1}\right)$ \\
\hline 1 & 0.051 & 0.060 & 0.051 & 0.047 \\
2 & 0.045 & 0.044 & 0.040 & 0.044 \\
3 & 0.360 & - & 0.259 & - \\
4 & 0.136 & - & 0.310 & - \\
5 & 0.035 & 0.025 & 0.023 & 0.021 \\
6 & 0.046 & 0.040 & 0.040 & 0.038 \\
7 & 0.028 & - & 0.025 & - \\
8 & 0.038 & - & 0.028 & - \\
9 & 0.036 & - & 0.033 & - \\
10 & 0.044 & - & 0.052 & - \\
11 & 0.035 & - & 0.034 & - \\
12 & 0.033 & 0.029 & 0.030 & 0.033 \\
\hline
\end{tabular}

chronic exposure and on the strain (Table 4). The interaction between strain and atrazine concentration was also significant, which indicates that the strains were affected differently by the chronic exposure (Table 4).

\section{Response Variability Among Strains}

The growth rate, photosynthetic activity, and short-term sensitivity data obtained for all 12 strains in the control and in the 5 $\mu \mathrm{g} \cdot \mathrm{L}^{-1}$ atrazine treatments were analyzed in terms of the range of response. The variability between strains in the control treatments was highest for the growth rate data, whereas the short-term sensitivity data varied less. Growth and photosynthesis in the chronic treatment ranged within values similar to those of the controls (Tables 2 and 3). However, the response range of the short-term sensitivity in the $5 \mu \mathrm{g} \cdot \mathrm{L}^{-1}$ atrazine treatments was wider than in the controls and the absolute values were lower (Table 3), indicating an increase in tolerance. This can also be seen in the breadth of the envelopes in the set of inhibition curves, which is widest at the lowest atrazine concentration and decreases with increasing exposure concentrations, a consequence of differences between strains in the rates of tolerance increase (Figure 2). Accordingly, the ranking of the short-term sensitivity also was different in the two treatments (Table 3).

\section{Discussion}

\section{Physiological Characteristics and Short-Term Sensitivity to Atrazine}

The 12 strains of S. subspicatus examined in this study differed in their geographic origin and morphology. They were assumed to be different genotypes. Under the given experimental conditions, differences occurred in the growth rates and in net oxygen evolution rates of acclimated cultures. Moreover, differences in the duration of the exponential growth phase were found even between strains that had similar exponential growth rates. This is probably due to differences in the acclimation rate of individual cells to the changing chemical conditions in the 
Table 3. Oxygen evolution and inhibition thereof by $500 \mu \mathrm{g} \cdot \mathrm{L}^{-1}$ atrazine during exponential growth of strains treated with 0 (control) and 5 $\mu \mathrm{g} \cdot \mathrm{L}^{-1}$ atrazine (values are means $\pm \mathrm{SE}, \mathrm{n}=2-3$ )

\begin{tabular}{|c|c|c|c|c|}
\hline \multirow[b]{2}{*}{ Strain } & \multicolumn{2}{|l|}{ Control } & \multicolumn{2}{|l|}{ Atrazine } \\
\hline & $\begin{array}{l}\text { Oxygen } \\
\text { Evolution } \\
\left(\mu \mathrm{M} \mathrm{O}_{2} \cdot \min ^{-1} \cdot \mathrm{OD}^{-1}\right)\end{array}$ & $\begin{array}{l}\text { Inhibition of } \\
\text { Oxygen Evolution } \\
(\% \text { of control })\end{array}$ & $\begin{array}{l}\text { Oxygen } \\
\text { Evolution } \\
\left(\mu \mathrm{M} \mathrm{O}_{2} \cdot \min ^{-1} \cdot \mathrm{OD}^{-1}\right)\end{array}$ & $\begin{array}{l}\text { Inhibition of } \\
\text { Oxygen Evolution } \\
(\% \text { of control })\end{array}$ \\
\hline 1 & $4.32 \pm 1.10$ & 48.0 & $5.51 \pm 0.90$ & 30.4 \\
\hline 2 & $2.32 \pm 0.01$ & 105.6 & $4.93 \pm 0.08$ & 24.6 \\
\hline 3 & $4.36 \pm 0.68$ & 55.6 & $5.68 \pm 0.62$ & 35.1 \\
\hline 4 & $6.61 \pm 1.33$ & 38.5 & $6.40 \pm 1.05$ & 29.8 \\
\hline 5 & $6.27 \pm 0.01$ & 95.2 & $5.40 \pm 0.25$ & 72.1 \\
\hline 6 & $11.04 \pm 1.41$ & 72.0 & $7.85 \pm 0.16$ & 51.7 \\
\hline 7 & $12.76 \pm 1.39$ & 65.3 & $4.85 \pm 1.19$ & 52.0 \\
\hline 8 & $6.21 \pm 1.60$ & 74.5 & $4.15 \pm 0.58$ & 4.5 \\
\hline 9 & $5.43 \pm 0.23$ & 36.4 & $5.20 \pm 0.45$ & 28.6 \\
\hline 10 & $9.36 \pm 1.41$ & 51.4 & $8.86 \pm 1.28$ & 34.2 \\
\hline 11 & $10.74 \pm 3.53$ & 41.2 & $6.83 \pm 1.42$ & 21.0 \\
\hline 12 & $8.90 \pm 0.74$ & 56.6 & $7.33 \pm 0.17$ & 72.9 \\
\hline
\end{tabular}

medium. Differences between strains were large in terms of growth rates, but smaller for photosynthetic activity. Comparative data are scarce, but are generally indicative of intraspecific variability for various biochemical and physiological traits, such as nutrient requirement for growth, nutrient metabolism, temperature-dependence of growth, or photosynthesis (Wood and Leatham 1992).

The short-term response of photosynthetic activity is a parameter commonly used to test the toxicity of herbicides to algae. The concentration of atrazine used in our experiments $\left(500 \mu \mathrm{g} \cdot \mathrm{L}^{-1}\right)$ was chosen so that all strains would be affected to some extent after short-term exposure. At this concentration, the short-term response of photosynthetic activity varied between strains by a factor of only three. Concentrations of atrazine similar to that applied in this study have been reported as being effective in the short-term inhibition of photosynthesis in various algal species (Hollister and Walsh 1973; Stratton 1984; Gonzalez et al. 1985; Larsen et al. 1986; Hersh and Crumpton 1989; Solomon et al. 1996) and phytoplankton assemblages (Gustavson and Wangberg 1995). It is remarkable that although this type of result has been obtained with different methods and conditions, atrazine concentrations that affect short-term photosynthetic activity in various species vary within a small range (Solomon et al. 1996). This may be related to the specificity of the primary effects of atrazine on photosynthesis, which are due to the intrinsic chemical properties of atrazine and to its binding to an evolutionary conserved site in photosystem II (Moreland 1980; Fedtke and Trebst 1987).

That between-strain differences in traits were still found after acclimation to the culture medium suggests that these differences have a genetic basis. This was confirmed by the significant influence of the factor "strain" on growth rate, net oxygen evolution, and inhibition thereof by atrazine.

\section{Effects of Chronic Exposure to Atrazine}

The concentrations of atrazine used in the chronic exposure (1, 5 , and $\left.20 \mu \mathrm{g} \cdot \mathrm{L}^{-1}\right)$ are commonly found in many agricultural watersheds (Huber 1993; Detenbeck et al. 1996; Solomon et al. 1996). These concentrations did not significantly affect the


Fig. 1. Temporal change of oxygen evolution in the presence of different concentrations of atrazine. Strains: $\square 1, \diamond 2, \bigcirc 5, \diamond 6, \mathbf{\square} 12$ 

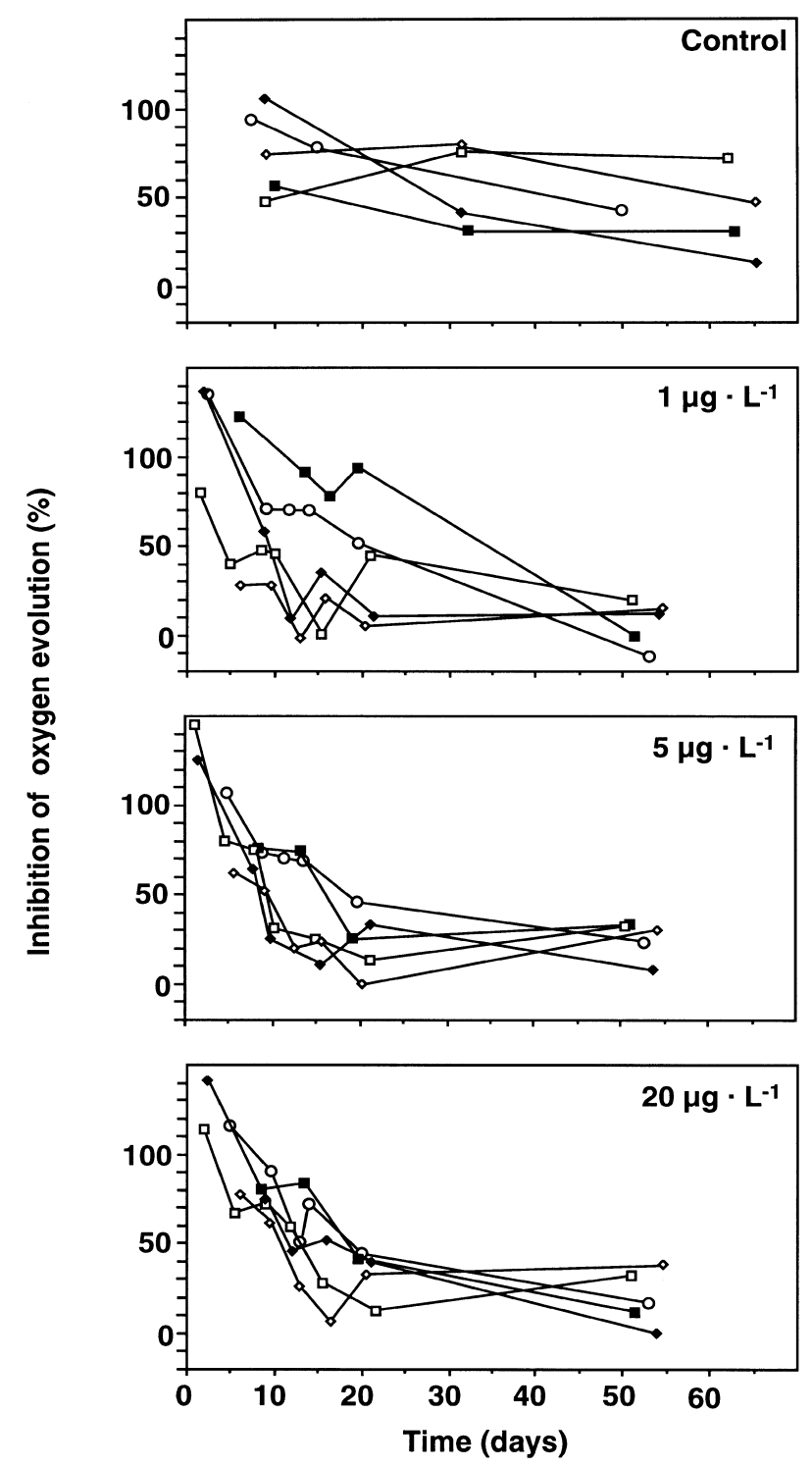

Fig. 2. Temporal change of inhibition of oxygen evolution in the presence of different concentrations of atrazine. Strains: $\square 1, \diamond 2, \bigcirc 5$, $\diamond 6, \mathbf{\square} 12$

Table 4. Test by ANOVA of the effects of strain (genotype), atrazine concentration (environment), and genotype-environment interaction on oxygen evolution and inhibition thereof by $500 \mu \mathrm{g} \cdot \mathrm{L}^{-1}$ atrazine $(\mathrm{n}=123)$

\begin{tabular}{|c|c|c|c|c|c|}
\hline \multirow[b]{2}{*}{ Factor } & \multirow[b]{2}{*}{ df } & \multicolumn{2}{|c|}{$\mathrm{O}_{2}$ Evolution } & \multicolumn{2}{|c|}{$\begin{array}{l}\text { Inhibition of } \\
\mathrm{O}_{2} \text { Evolution }\end{array}$} \\
\hline & & $\mathrm{F}$ & $\alpha$ & $\mathrm{F}$ & $\alpha$ \\
\hline Strain & 11 & 4.64 & 0.014 & 5.34 & 0.009 \\
\hline Concentration & 3 & 2.14 & 0.17 & 7.00 & 0.01 \\
\hline Strain $\times$ concentration & 19 & 1.16 & 0.42 & 5.48 & 0.0064 \\
\hline
\end{tabular}

growth rate or the net photosynthetic activity of the various strains. In algae there is, however, a high interspecific variability in sensitivity to atrazine (Huber 1993): Minimal concentrations of atrazine reported to affect photosynthesis and growth rate of phytoplankton range from as low as $1 \mu \mathrm{g} \cdot \mathrm{L}^{-1}$ for communities (De Noyelles et al. 1982; Lillelund et al. 1987; Lampert et al. 1989) to $1,000 \mu \mathrm{g} \cdot \mathrm{L}^{-1}$ for single species (Hollister and Walsh 1973; Butler 1977; Larsen et al. 1986; Hersh and Crumpton 1987). Most of the studies reporting high effective atrazine concentrations were done on pure algal cultures under short exposure times. Other studies conducted on the chronic impact of low atrazine concentrations have reported successional effects (De Noyelles et al. 1982; Gustavson and Wangberg 1995). On the basis of toxicity data, including laboratory bioassays and microcosm, mesocosm, and field studies, atrazine concentrations up to $20 \mu \mathrm{g} \cdot \mathrm{L}^{-1}$ are not considered to represent a problem for aquatic ecosystems (Huber 1993; Solomon et al. 1996).

In this study, chronic exposure to low atrazine levels did strongly affect the short-term photosynthetic response to 500 $\mu \mathrm{g} \cdot \mathrm{L}^{-1}$ atrazine. All strains except one, when treated with 1,5 , or $20 \mu \mathrm{g} \cdot \mathrm{L}^{-1}$ atrazine, were less sensitive than control cultures. An increase in tolerance was obvious after a few days in culture, and it increased during the first 15 days. The rate of tolerance increase was proportional to the atrazine concentration in the chronic exposure. Such a tolerance increase, as well as its temporal dynamics, may result from a homeostatic mechanism triggered by the exposure to atrazine. Low atrazine concentrations have been shown to induce a reorganization of the photosynthetic apparatus of algae similar to the adaptive reorganization induced by low light intensities (Hatfield et al. 1989; König 1990). Responses such as the synthesis of thylakoid components are considered to be a general adaptation response to situations in which electron transport rate is limited for photosynthesis (Melis et al. 1985).

The ecotoxicological interpretation of the increase in tolerance of short-term photosynthetic response is not obvious. This increase may reflect a cellular perturbation or just a reaction that allows to sustain growth and photosynthesis under altered cellular conditions. The answer remains elusive even though we know that the photosynthetic activity of the various strains treated with atrazine was similar to that of the control strains. In fact, it is conceivable that a combination of stress factors that limit electron transport would demand an energy allocation for mechanistic compensation too high to maintain photosynthesis or growth.

The rank order of short-term photosynthetic sensitivity of strains was different for the various chronic treatments. There was a significant genotype $\times$ environment interaction, which reflected a difference in response to increments in atrazine concentration in the chronic exposure. Along with the change in rank order of strain response under increasing atrazine exposure levels a change occurred in the variability of response between strains. The range of response covered by the strains cultured at $5 \mu \mathrm{g} \cdot \mathrm{L}^{-1}$ was markedly higher $(4.5-72.9 \%)$ than that in the strains cultured in the absence of atrazine (36.4-105.6\%). This agrees with observations that moderate chemical stress can lead to an increase in the variability of biological traits at various levels of organization (Forbes and Depledge 1996).

Few studies have tested the influence of genotype and of genotype $X$ environment interactions on the response of aquatic organisms to toxic stress (Baird et al. 1991; Münziger and Monicelli 1991; Soares et al. 1992; Forbes et al. 1995). Yet, these studies point to the significance of intraspecific phenotypic variability and its bearing on the design of ecotoxicologi- 
cal studies. When the goal is to compare results and protocols between laboratories, the designation of the strain or clone and the description of the culture medium used are essential. On the other hand, when the goal is to assess the impact of a chemical on a species, intraspecific variability should be regarded as a key parameter affecting the potential for evolution of tolerance to environmental stress.

\section{References}

Baird DJ, Barber I, Bradley M, Soares AMVM, Calow P (1991) A comparative study of genotype sensitivity to acute toxic stress using strains of Daphnia magna Straus. Ecotoxicol Environ Saf 21:257-265

Butler GL (1977) Algae and pesticides. Residue Rev 66:19-62

Brand LE, Guillard RRL (1981) A method for the rapid and precise determination of acclimated phytoplankton reproduction rates. J Plankton Res 3:193-201

Davoli E, Benfenati E, Bagnati R, Fanelli R (1987) Analysis of atrazine in underground waters at part per trillion levels as an early warning method for contamination and for soil distribution studies. Chemosphere 16:1425-1430

Delieu T, Walker DA (1972) An improved cathode for the measurement of photosynthetic oxygen evolution by isolated chloroplasts. New Phytol 7:201-255

DeNoyelles F, Kettle D, Sinn DE (1982) The responses of plankton communities in experimental ponds to atrazine, the most heavily used pesticide in the United States. Ecology 63:1285-1293

Detenbeck NE, Hermanutz R, Allen K, Swift M (1996) Fate and effects of the herbicide atrazine in flow-through wetland mesocosms. Environ Toxicol Chem 15:937-946

Fedtke C, Trebst A (1987) Advances in understanding herbicide modes of action. In: Greenhalgh R, Roberts TR (eds). Pesticide science and biotechnology. Blackwell Scientific Publications, Oxford, pp $161-168$

Feldman DS, Gagnon J, Hofmann R, Simpson J (1987) StatView II. Abacus Concepts, Berkeley, CA

Fisher NS, Graham LB, Carpenter EJ, Wurster CF (1973) Geographic differences in phytoplankton sensitivity to PCBs. Nature 241:548549

Forbes VE, Depledge MH (1996) Environmental stress and the distribution of traits within populations. In: Baird DJ, Maltby L, Greig-Smith PW, Douben PET (eds) Ecotoxicology: ecological dimensions. Chapman and Hall, London, pp 71-86

Forbes VE, Forbes TL (1994) Ecotoxicology in theory and praxis. Chapman and Hall, London, pp 129-148

Forbes VE, Moller V, Depledge MH (1995) Intrapopulation variability in sublethal response to heavy metal stress in sexual and asexual gastropod populations. Funct Ecol 9:477-484

Foster PL (1982) Metal resistances of Chlorophyta from rivers polluted by heavy metals. Fresh Biol 12:41-61

Gad SC, Weil CS (1989) Statistics for toxicologists. In: Hayes AW (ed) Principles and methods of toxicology, 2d ed. Raven Press, New York, NY, pp 435-483

Gonzalez-Murua C, Munos-Rueda A, Hernando F, Sanchez-Diaz M (1985) Effect of atrazine and methabenzthiazuron on oxygen evolution and cell growth of Chlorella pyrenoïdosa. Weed Res 25:61-66
Gustavson K, Wangberg S-A (1995) Tolerance induction and succession in microalgae communities exposed to atrazine. Aquat Toxicol 32:283-302

Hatfield PM, Guikema JA, St John JB, Gendel SM (1989) Characterization of the adaptation response of Anacystis nidulans to growth in the presence of sublethal doses of herbicide. Curr Microbiol 18:369-374

Hersh CM, Crumpton WG (1987) Determination of growth rate depression of some green algae by atrazine. Bull Environ Contam Toxicol 39:1041-1048

(1989) Atrazine tolerance of algae isolated from two agricultural streams. Environ Toxicol Chem 8:327-332

Hoffmann AA, Parsons PA (1991) Evolutionary genetics and environmental stress. Oxford University Press, Oxford

Hollister TA, Walsh GE (1973) Differential responses of marine phytoplankton to herbicides: oxygen evolution. Bull Environ Contam Toxicol 9:291-295

Huber W (1993) Ecotoxicological relevance of atrazine in aquatic systems. Environ Toxicol Chem 12:1865-1881

König F (1990) Shade adaptation in cyanobacteria. Photosynth Res 26:29-37

Lampert W, Flechner W, Pott E, Schober U, Störkel KU (1989) Herbicide effects on planktonic systems of different complexity. Hydrobiologica 188/189:415-424

Larsen DP, De Noyelles F, Stay F, Shiroyama T (1986) Comparisons of single-species, microcosm and experimental pond responses to atrazine exposure. Environ Toxicol Chem 5:179-190

Lillelund K, de Haar U, Elster HJ, Karbe L, Schwörbel I, Simonis W (1987) Bioakkumulation in Nahrungsketten. DFG Forschungsbericht, VHC Weinheim, Germany

Melis A, Manodori A, Glick RE, Ghirardi ML, McCauley SW, Neale PJ (1985) The mechanism of photosynthetic membrane adaptation to environmental stress conditions: a hypothesis on the role of electron transport capacity and of ATP/NADPH pool in the regulation of thylakoid membrane organization and function. Physiol Veg 23:757-765

Menzel DW, Anderson J, Randke A (1970). Marine phytoplankton vary in their response to chlorinated hydrocarbons. Science 167:17241726

Moreland DE (1980) Mechanisms of action of herbicides. Ann Rev Plant Physiol 31:597-638

Murphy LS, Belastock RA (1980) The effect of environmental origin on the response of marine diatoms to chemical stress. Limnol Oceanogr 25:160-165

Münziger A, Monicelli F (1991) A comparison of the sensitivity of three Daphnia magna populations under chronic heavy metal stress. Ecotoxicol Environ Saf 22:24-31

Soares AMVM, Baird DJ, Calow P (1992) Interclonal variation in the performance of Daphnia magna Straus in chronic bioassays. Environ Toxicol Chem 11:1477-1483

Sokal RR, Rohlf FJ (1981) Biometry, 2d ed. Freeman, New York, NY

Solomon KR, Baker DB, Richards RP, Dixon KR, Klaine SJ, La Point TW, Kendall RJ, Weisskopf CP, Giddings JM, Giesy JP, Hall LW Jr, Williams WM (1996) Ecological risk assessment of atrazine in North American surface waters. Environ Toxicol Chem 15:31-76

Stein JR (1973) Phycological methods. Cambridge University Press, London

Stratton GW (1984) Effects of the herbicide atrazine and its degradation products, alone and in combination, on phototrophic microorganisms. Arch Environ Contam Toxicol 13:35-42

Wood AM, Leatham T (1992) The species concept in phytoplancton ecology. J Phycol 28:723-729 